\title{
Degradación del colorante Rojo Punzó por medio de lodos anaerobios
}

\author{
María Elena González Duque ${ }^{1}$, Joan Amir Arroyave Rojas², \\ Julieta Mejía Trujillo3, Stefania del Pilar Arias Gómez ${ }^{3}$, \\ Johanna Marcela Osorio Bermúdez ${ }^{3}$, \\ Gonzalo de Jesús Restrepo Martínez ${ }^{3}$
}

1. Bacterióloga, Especialista en Gestión Ambiental. Docente de cátedra e investigadora del grupo de investigación GAMA, Facultad de Ingenierías, Corporación Universitaria Lasallista.

2. Ingeniero Sanitario, Especialista en Construcción Sostenible, Candidato a Magíster en Ingeniería Ambiental. Docente e Investigador del grupo de investigación Ambiente y Hábitat, Facultad de Arquitectura e Ingeniería, Institución Universitaria Colegio Mayor de Antioquia.

3. Estudiante Ingeniería Ambiental, Corporación Universitaria Lasallista. Semillero de Investigación en Gestión y Medio Ambiente SIGMA. Grupo de Investigación GAMA.

Correspondencia: megonzal27@gmail.com

Recibido: 03-17-10 / Aceptado: 05-28-10

\section{Resumen}

La presencia de vertimientos líquidos con contenidos de colorantes ha generado deterioro en la calidad del agua de las fuentes que reciben estas descarga, desfavoreciendo sus características estéticas, organolépticas y la presencia de fauna íctica debido a las interferencias que provocan con el ingreso luz natural para que se de la productividad primaria en estos ecosistemas, de esta forma se deterioran los eslabones en la cadena trófica y la pérdida de biodiversidad; es por ello, que es importante las iniciativas para disminuir la demanda de bienes y servicios ambientales, además, de los pasivos ambientales entorno a los vertimientos coloreados, de esta forma, mediante este estudio de degradación del colorante rojo Punzó se pretende dar solución e incrementar la capacidad técnica y científica entorno al tratamiento de efluentes con presencia de colorantes azoicos como es el caso del rojo Punzó. El presente trabajo determinó la biodegradabilidad anaerobia del colorante Rojo Punzó empleando recuentos microbianos. Palabras clave: Digestión anaerobia, ecología microbiana, colorantes azoicos, Rojo Punzó.

\section{Abstract \\ Ponceau Red dye degradation by anaerobic sludge}

The presence of colored liquid effluents generated deterioration in the quality of watersources that receive disfavoring its aesthetic characteristics, sensory and presence of fish fauna due to interference with the entrance leading to natural light so that the primary productivity in these ecosystems, thus deteriorate the links in the food chain and loss of biodiversity is therefore, important initiatives to reduce the demand for environmental goods and services also environmental liabilities around the discharges colored in this way, through the study of degradation of the red dye Ponceau aims to address and improve the technical and scientific environment to the effluent treatment in the presence of azo dyessuch as Ponceau red. This study determined the anaerobic biodegradability of PonceauRed dye using microbial counts.

Keywords: Anaerobic digestion, microbial ecology, azo dyes, Ponceau Red. 


\section{Introducción}

Uno de los problemas ambientales más serios son los ocasionados por efluentes con color provenientes de procesos industriales, siendo los colorantes azóicos los más usados en la industria textil, alimentaria(1-6), papelera y de cosméticos entre otras; luego, son vertidos a los efluentes sin ningún tratamiento ocasionando consecuencias graves para el ambiente debido a que poseen una alta carga contaminante y son difíciles de degradar, además tienen efectos perjudiciales para la salud debido a sus propiedades carcinogénicas, alergénicas y mutagénicas $(7,8)$. El color puede ser removido por procesos fisicoquímicos $(9,10)$ pero la consecuencia es agregar más contaminación al ambiente; también pueden ser degradados por procesos biológicos $(11,12)$. Estos últimos tienen la ventaja de ser más amigables para el ambiente y más económicos comparados con los tratamientos físico-químicos (13) constituyéndose en una alternativa ecológica y económicamente viable para su degradación; dentro de estos procesos se encuentra la digestión anaerobia, este es un proceso microbiológico mediante el cual la materia orgánica se convierte a metano, dióxido de carbono e hidrógeno en ausencia de oxígeno y a causa de la acción combinada de diferentes poblaciones microbianas como las bacterias anaerobias facultativas y obligadas; las cuales utilizan en forma secuencial los productos metabólicos generados por cada grupo; la caracterización de la biomasa es importante por cuanto permite entender el funcionamiento del sistema por la calidad y cantidad de microorganismos presentes $(14,15)$. Este proceso ha sido ampliamente estudiado en la degradación de colorantes (16-19).

El desarrollo de diferentes sectores industriales en la actualidad ha dependido del empleo de productos y aditivos artificiales; entre los sectores industriales en los cuales se aplican estos de manera intensiva ha sido la industria de los alimentos la cual incorpora dichos productos en la formulación, procesamiento y producto terminado. De la gran cantidad de aditivos que existen, los colorantes comprenden una familia amplia que atrae la atención de los profesionales de la ciencia de los alimentos por las numerosas aplicaciones y generación de nuevos productos; por otro lado, se ha puesto atención debido a diferentes afirmaciones, unas con fundamento y otras simples especulaciones, sobre sus efectos adversos en la salud de los consumidores $(1,2)$.

El Rojo Punzó es uno de los colorantes artificiales más utilizados en la industria de alimentos 1 para la elaboración de productos cárnicos, mermeladas, especias y frutas procesadas; y pertenece a la familia de los colorantes azoicos (2); dicho colorante le confiere a los alimentos y bebidas un tono rojo, por otro lado se emplea para obtener diferentes gamas de colores cálidos en las mezclas alimenticias para diferentes productos como golosinas, bebidas, carnes frías, entre otros productos.

El colorante artificial rojo punzó $4 \mathrm{R}$ consiste fundamentalmente en 2-hidroxi-1-(-4-sulfonato-1naftilazo)- Naftaleno -6,8-disulfonato trisódico, junto con cloruro sódico o sulfato sódico como principales componentes incoloros. Éste se describe como sal sódica y el empleo de cualquier tipo de colorante se debe regular según las cantidades permitidas por la legislación, tal como rezan el Decreto 2106 de 1983 y la Resolución 10593 de 1985, los cuales establecen las normas para prevenir peligros para la salud de los consumidores, cuyas dosificaciones son el resultado de investigaciones, ya que estos productos no se consideran inocuos del todo (Madrid, 2000).

De esta forma, se observa que este colorante es un producto sintético de un espectro amplio de utilización, en investigaciones recientes se ha tratado de generar productos sustitutos para dicho colorante buscando reducir el consumo de dicho producto, debido a que éste se ha ido desfavoreciendo por algunos posibles efectos segundarios en su consumo debido a que este tipo de colorante no se consideran inocuos totalmente (Revista Épsilon, Sustitución), para lo cual se recomienda a los titulares de productos clasificados como alimentos o cualquier otro uso industrial que contengan Rojo Punzó deben reportar en la etiqueta del producto elaborado o terminado el contenido de dicho colorante (Resolución 10593/85); debido a que este puede provocar reacciones de tipo alérgico, asma, especialmente en pacientes alérgicos al ácido acetil salicílico, Ficha técnica.

La implementación de programas de producción más limpia enmarcados en la disminución de vertimiento y efluentes contaminantes, y en especial 


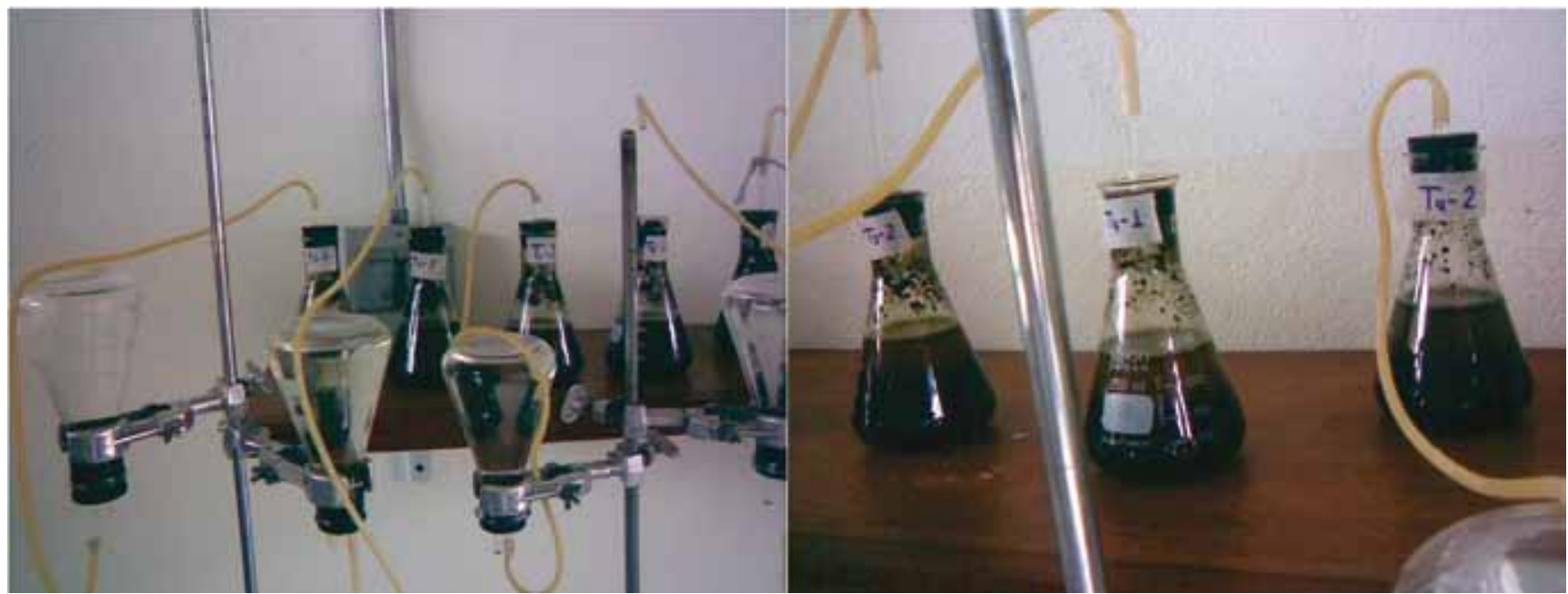

Figura 2. Reactores Bath para la degradación anaerobia del colorante Rojo Punzó.

Tabla 1. Condiciones de los experimentos para el colorante Rojo

Punzó y el cosustrato almidón.

\begin{tabular}{ccc|}
$\begin{array}{c}\text { Experimento } \\
\text { No. }\end{array}$ & $\begin{array}{c}\text { Concentración } \\
\text { colorante }(\mathbf{m g} / \mathbf{L})\end{array}$ & $\begin{array}{c}\text { Concentración } \\
\text { cosustrato }(\mathbf{m g} / \mathbf{L})\end{array}$ \\
\hline E1 & 1000 & 0 \\
E2 & 500 & 0 \\
E3 & 1000 & 100 \\
E4 & 500 & 50 \\
E5 & 1000 & 50 \\
E6 & 500 & 100 \\
E7 & 0 & 50 \\
E8 & 0 & 100 \\
E9 - Control & 0 & 0 \\
\hline
\end{tabular}

Tabla 2. Diseño experimental factorial de dos factores.

\begin{tabular}{lr}
\hline \multicolumn{1}{c}{ Variables } & Niveles \\
\hline Concentración del colorante & $0 \mathrm{mg} / \mathrm{L}$ \\
(Rojo Punzó) & $500 \mathrm{mg} / \mathrm{L}$ \\
& $1000 \mathrm{mg} / \mathrm{L}$ \\
Concentración del & $0 \mathrm{mg} / \mathrm{L}$ \\
cosustrato (Almidón) & $50 \mathrm{mg} / \mathrm{L}$ \\
& $100 \mathrm{mg} / \mathrm{L}$
\end{tabular}

\section{Modelo del diseño estadístico}

$$
\mathbf{Y}_{\mathrm{ijk}}=\mu+\alpha_{\mathrm{i}}+\beta_{\mathrm{j}}+(\alpha \beta)_{\mathrm{ij}}+\varepsilon_{\mathrm{ijk}}
$$

En donde,

$\mathbf{Y}_{\mathrm{ijk}}=$ Es la k-ésima observación del porcentaje de degradación del colorante Rojo Punzó, observado en los niveles i y j de los factores concentración de colorante y la concentración del cosustrato.

$\mu=$ Es el porcentaje medio de remoción o degradación del colorante Rojo Punzó en el modelo.

$\alpha=$ Es el efecto del i-ésimo nivel del factor concentración del colorante Rojo Punzó; i = 0, 500 y 1000 mg/L.

$\beta=$ Es el efecto del j-ésimo nivel del factor concentración del co-sustrato; $j=0,50$ y $100 \mathrm{mg} / \mathrm{L}$.

$\alpha_{\beta i j}=$ Es el efecto de la interacción entre los niveles i y j de los factores concentración de colorante y la concentración del cosustrato.

$\varepsilon_{\mathrm{ijk}}=$ Es el k-ésimo término de error aleatorio.

Análisis de resultados. En la tabla 3 y la figura 3 se presentan los resultados obtenidos en la realización

Tabla 3. Porcentaje de degradación de colorantes.

\begin{tabular}{ccc}
\hline Rojo Punzó $(\mathbf{m g} / \mathbf{L})$ & Cosustrato $(\mathbf{m g} / \mathbf{L})$ & \% Remoción \\
\hline 0,0 & 0,0 & $0,00 \%$ \\
0,0 & 50,0 & $0,00 \%$ \\
0,0 & 100,0 & $0,00 \%$ \\
500,0 & 0,0 & $93,28 \%$ \\
500,0 & 50,0 & $93,29 \%$ \\
500,0 & 100,0 & $94,18 \%$ \\
1000,0 & 0,0 & $93,06 \%$ \\
1000,0 & 50,0 & $90,08 \%$ \\
1000,0 & 100,0 & $90,64 \%$ \\
\hline
\end{tabular}


de las corridas experimentales para las diferentes combinaciones de colorante y cosustrato mediante el tratamiento de biodegradación anaerobia del colorante rojo Punzó empleando recuentos microbianos.

Se observa en los resultados obtenidos para las diferentes combinaciones experimentales que poseen porcentajes de degradación superiores al 90\% del colorante rojo Punzó; de esta forma se evidencia que dicho colorante es biodegradable por vía anaerobia en el lodo evaluado, el cual posee los tipos de microbios adecuados para la degradación de colorantes azoicos como es el caso del colorante rojo Punzó.

Como se evidencia en la Figura 1, las combinaciones experimentales que contienen colorante muestran un elevado porcentaje de remoción de este, obteniéndose el mayor porcentaje de degradación para la combinación experimental 500 mg/L de rojo Punzó y $100 \mathrm{mg} / \mathrm{L}$ de cosustrato; por otro lado, observando la presencia y la generación de costos adicionales por el suministro y adición de reactivos como el cosustraro; se puede considerar que la combinación experimental más apropiada es $500 \mathrm{mg} / \mathrm{L}$ de rojo Punzó y 0 mg/L de cosustrato, la cual alcanzó un porcentaje de biodegradación del $93.28 \%$; el cual es un porcentaje de remoción del colorante significativo.

Adicionalmente, se aprecia que la presencia de cosustrato no obtuvo una respuesta positiva en el logro de la degradación del colorante rojo Punzó; por otro lado, se puede evidenciar que la presencia de cosustrato favorece la disminución de los resultados en la variable respuesta evaluada en el presente proyecto, es decir, en el porcentaje de biodegradación o remoción del colorante rojo Punzó; si se observan todas las combinaciones en las cuales interviene el cosustrato, se evidencia que los porcentajes de remoción relativamente similares. Sin embargo, cuando se incrementa la concentración del colorante, es decir para los ensayos realizados con 1000 mg/L de rojo Punzó; se presenta una reducción en la biodegradación del mismo; esto nos permite evidenciar que a concentraciones superiores del colorante se comporta como un compuesto persistente y recalcitrante que es difícil de degradar por vía anaerobia en el cual los microorganismos se apropian de los sustratos de mayor facilidad para su biodegradación, en este caso del almidón que se

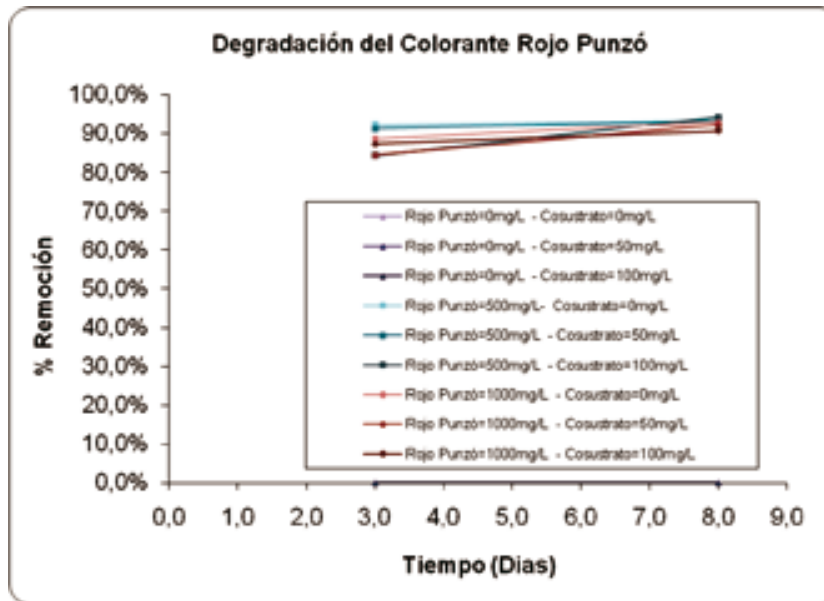

Figura 3. Degradación del Colorante Rojo Punzó mediante el recuento microbiano.

incorporo como cosustrato para potenciar la acción de la remoción del colorante rojo Punzó.

De esta forma, se evidencia que el incremento en la concentración del colorante genero una disminución en la remoción del mismo provocando una reducción en la actividad biológica en la biodegradación del colorante rojo Punzó. Por otro lado, se realizo la medición de la generación de biogás en el tratamiento anaerobio de la biodegradación del colorante rojo Punzó, sin embargo, los datos obtenidos no fueron concluyentes debido a que el método empleado no arrojo datos confiables, por lo tanto, no se presentan en este texto debido a las dificultades inherentes a dicho proceso de medición; se presentaron desalojos parciales y/o totales por inconvenientes en la instalación de los dispositivos de desplazamiento de volumen, generando imprecisiones en las lecturas obtenidas en las diferentes corridas experimentales.

Adicionalmente, a la cuantificación de los parámetros fisicoquímicos para determinar la biodegradación del colorante rojo Punzó se realizaron recuentos microbianos de los microorganismos más representativos en los procesos de degradación anaerobia. En la tabla 4 se presentan los resultados obtenidos en la cuantificación inicial de la caracterización microbiológica del lodo empleado para la biodegradación del colorante rojo Punzó.

Como se puede apreciar en dicha tabla, el lodo empleado posee un adecuado consorcio microbiano el cual se empleó para realizar los diferentes tratamientos experimentales con el fin de lograr la biodegradación del colorante azoico rojo Punzó. 
Tabla 4. Recuentos microbianos del lodo inicial.

\begin{tabular}{lc}
\multicolumn{1}{c}{ Tipo de microorganismo } & Concentración (UFC/mL) \\
\hline Levaduras: & $3.4 \times 10^{4}$ \\
Lactobacilos & $4.0 \times 10^{3}$ \\
Bacterias Facultativas & $7.4 \times 10^{6}$ \\
Bacterias Lipoliticas & $3.5 \times 10^{6}$ \\
Bacterias Anaerobias & $1.8 \times 10^{6}$ \\
Bacterias Sulfatoreductoras & $2.0 \times 10^{2}$ \\
\hline
\end{tabular}

Posterior a realizar los tratamientos experimentales con las diferentes combinaciones y corridas para la estudiar la biodegradación del colorante rojo Punzó se obtuvo los recuentos finales de los consorcios microbianos, los cuales se presentan en la Tabla 5, en donde se evidencia que se presentó un incremento en el número de microorganismos para los grupos evaluados durante el proceso de la biodegradación anaerobia del colorante en estudio; se evidencia que se generó una aclimatación y acondicionamiento del consorcio de microorganismos al sustrato a degradar, adicionalmente, se observa que se produjo un incremento en la población de microorganismos para los diferentes tipos como consecuencia de la generación de biomasa en los diferentes tratamientos experimentales.

De acuerdo a los resultados consignados en la Tabla 5, se encuentra que los grupos de bacterias anaerobias obligadas y facultativas incrementaron su número, lo cual es relevante en los procesos de biodegradación anaerobia, debido a que estos grupos son importantes de acuerdo a la ecología microbiana que se debe presentar en los reactores anaerobios; debido a que las bacterias facultativas utilizan el oxígeno y disminuyen la presión de este creando un ambiente anaerobio que es necesario para el crecimiento de las bacterias anaerobias obligadas que se benefician del metabolismo de las facultativas; esta relación es llamada Comensalismo (21).

Adicionalmente, en la Figura 4 se presentan los mayores recuentos de bacterias facultativas y anaerobias obligadas para el tratamiento $0 \mathrm{mg} / \mathrm{L}$ rojo Punzó y 100 mg/L de cosustrato; esto se entiende por cuanto un sustrato como el almidón es fácil de degradar comparado con un colorante azoico como

Tabla 5. Recuentos microbianos del lodo después de los tratamientos de degradación del colorante Rojo Punzó.

\begin{tabular}{|c|c|c|c|c|c|c|c|c|c|}
\hline 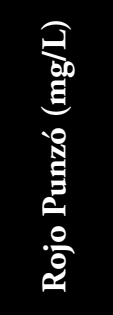 & 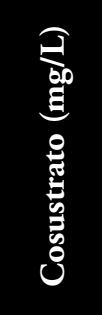 & 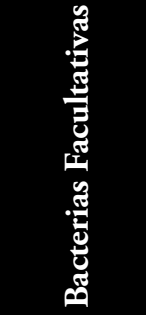 & 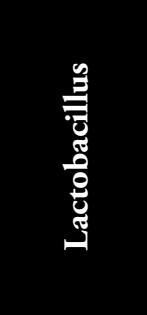 & 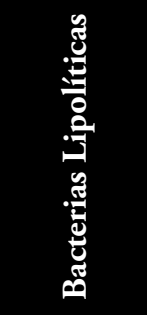 & 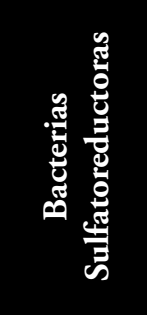 & 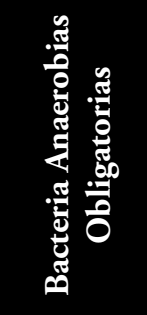 & 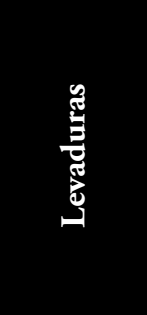 & $\frac{8}{\frac{8}{0}}$ & 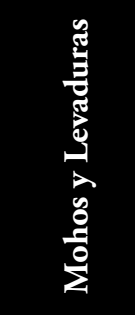 \\
\hline 0,0 & 0,0 & $1,4 \times 10^{7}$ & $3,8 \times 10^{3}$ & $8,2 \times 10^{5}$ & $8,0 \times 10^{3}$ & $6,0 \times 10^{5}$ & $2,5 \times 10^{5}$ & $1,5 \times 10^{4}$ & $2,6 \times 10^{5}$ \\
\hline 0,0 & 50,0 & $2,8 \times 10^{7}$ & $1,5 \times 10^{4}$ & $3,0 \times 10^{7}$ & $5,0 \times 10^{2}$ & $3,0 \times 10^{7}$ & $2,5 \times 10^{7}$ & $2,0 \times 10^{5}$ & $2,5 \times 10^{7}$ \\
\hline 0,0 & 100,0 & $1,8 \times 10^{8}$ & $3,5 \times 10^{4}$ & $8,0 \times 10^{6}$ & $5,0 \times 10^{2}$ & $1,8 \times 10^{8}$ & $1,8 \times 10^{5}$ & $2,0 \times 10^{3}$ & $1,8 \times 10^{5}$ \\
\hline 500,0 & 0,0 & $1,4 \times 10^{6}$ & $3,0 \times 10^{4}$ & $1,8 \times 10^{6}$ & $2,6 \times 10^{4}$ & $1,1 \times 10^{7}$ & $1,4 \times 10^{5}$ & $2,0 \times 10^{3}$ & $1,4 \times 10^{5}$ \\
\hline 500,0 & 50,0 & $3,0 \times 10^{6}$ & $9,0 \times 10^{3}$ & $8,0 \times 10^{5}$ & $1,0 \times 10^{5}$ & $4,0 \times 10^{6}$ & $2,7 \times 10^{5}$ & $1,1 \times 10^{4}$ & $2,9 \times 10^{5}$ \\
\hline 1000,0 & 50,0 & $5,0 \times 10^{6}$ & $7,0 \times 10^{3}$ & $2,3 \times 10^{6}$ & $6,0 \times 10^{3}$ & $6,0 \times 10^{6}$ & $1,0 \times 10^{5}$ & N.D. & $1,0 \times 10^{5}$ \\
\hline 1000,0 & 100,0 & $4,5 \times 10^{6}$ & $1,1 \times 10^{4}$ & $1,5 \times 10^{6}$ & $1,8 \times 10^{5}$ & $1,0 \times 10^{7}$ & $1,8 \times 10^{6}$ & $1,5 \times 10^{5}$ & $2,0 \times 10^{6}$ \\
\hline
\end{tabular}

N.D. Negativo en la menor dilución sembrada. 
el rojo Punzó debido a sus características persistentes y recalcitrantes, lo que requiere mayor trabajo de las bacterias para su biodegradación.

Se empleo una análisis de varianza - ANOVA para observar el comportamiento estadístico de los datos experimentales; como se aprecia en la Tabla 6; de acuerdo a los valores arrojados de $\mathrm{P}(\mathrm{p}<0,05)$ se evidencia que para el factor concentración del colorante rojo Punzó se tiene una variación significativa en la variable respuesta, es decir en el porcentaje de biodegradación del colorante rojo punzó, por otro lado, se observa que para el factor del cosustrato - Almidón, no se presenta una variación significativa de los porcentajes de remoción del colorante. Por lo tanto, los resultados obtenidos del modelo estadístico empleado, sirven para explicar la biodegradación del colorante azoico rojo punzó de acuerdo a los factores definidos, teniendo mayor influencia el factor de la concentración del colorante comparado con la variable del cosustrato.

Adicionalmente, se evidencia que la interacción doble entre los dos factores, concentración de colorante y concentración de cosustrato, no coadyuvan para lograr mejores remociones o resultados de la variable respuesta la cual es la biodegradación del colorante rojo Punzó.

En la Figura 5 se observa el método utilizado para identificar las diferencias significativas de Fisher (LSD), en donde se tiene que para la interrelación entre la concentración del cosustrato, no se presentan diferencias significativas entre las medias obtenidas experimentalmente para 0,50 y $100 \mathrm{mg} / \mathrm{L}$ de almidón.

De igual forma en la Figura 6, se observa que para los intervalos de los niveles de la concentración del colorante rojo Punzó con un nivel de confianza del 95\%, las variaciones de las medias entre $0-500 \mathrm{mg} / \mathrm{L}$ y $0-1000 \mathrm{mg} / \mathrm{L}$ de rojo Punzó, poseen diferencias significativas entre los niveles experimentales y la variable respuesta, es decir, la remoción o biodegradación del

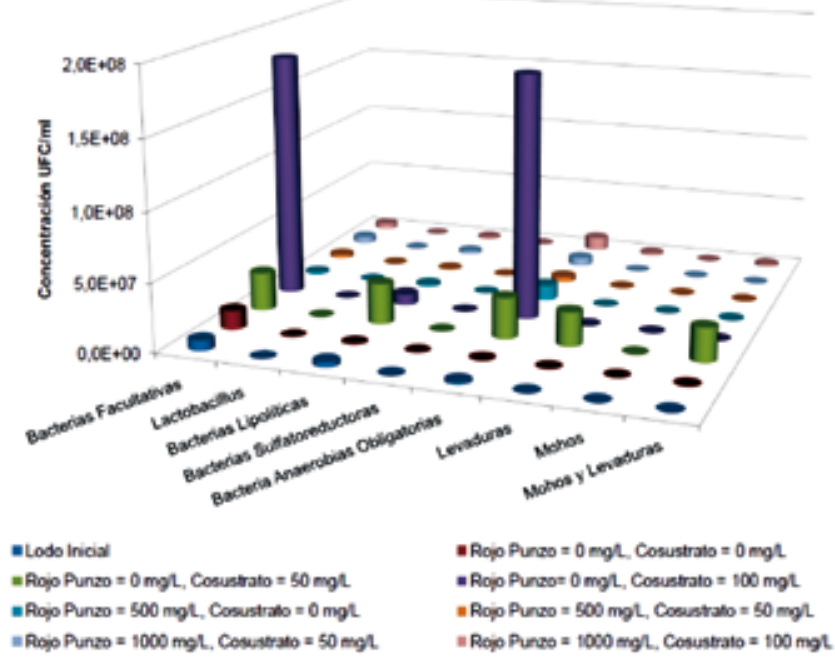

Figura 4. Ecología microbiana de la digestión anaerobia del colorante rojo punzó.

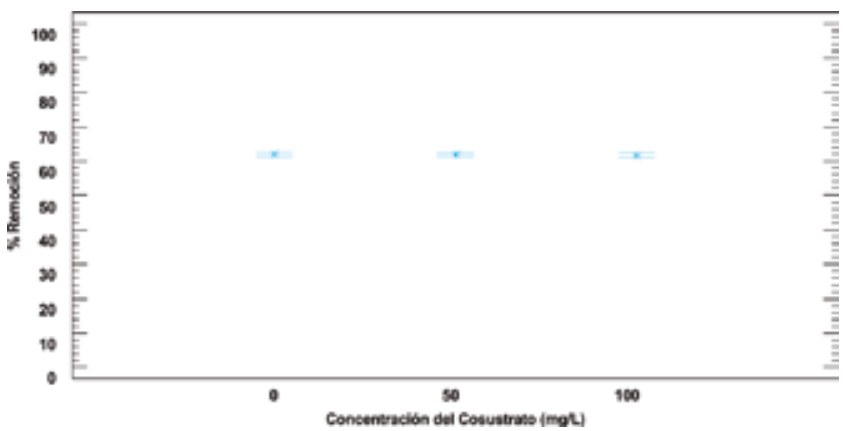

Figura 5. Medias e Intervalos de Confianza 95\% LSD para el Cosustrato.

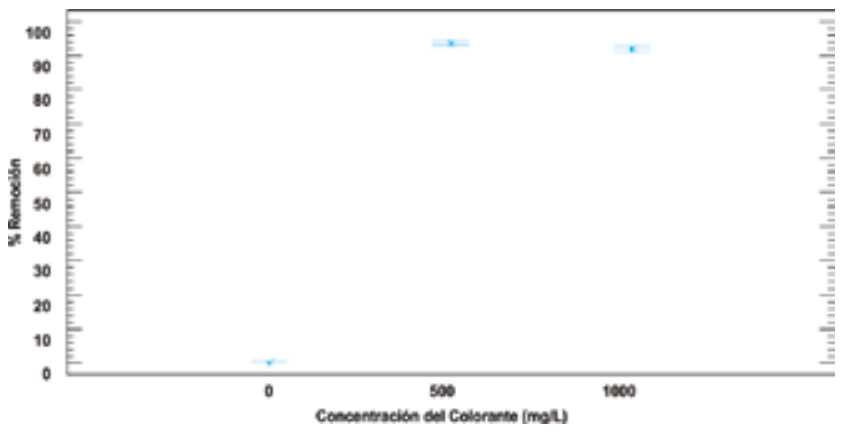

Figura 6. Medias e intervalos de confianza 95\% LSD para el rojo punzó.

Tabla 6. Análisis estadístico ANOVA de los datos experimentales.

\begin{tabular}{lccccc}
\multicolumn{1}{c}{ Fuente } & $\begin{array}{c}\text { Grados de } \\
\text { Libertad }\end{array}$ & $\begin{array}{c}\text { Suma de } \\
\text { Cuadrados }\end{array}$ & $\begin{array}{c}\text { Promedio al } \\
\text { Cuadrado }\end{array}$ & Coeficiente F & Valor de p \\
\hline $\begin{array}{l}\text { A: Concentración de } \\
\text { Rojo Punzó }\end{array}$ & 2 & 51670,2 & 25835,1 & 16132,00 & 0,0000 \\
$\begin{array}{l}\text { B: Concentración de } \\
\text { Cosustrato }\end{array}$ & 2 & 1,22741 & 0,613704 & 0,38 & 0,6871 \\
Interacción AB & 4 & 9,5037 & 2,37593 & 1,48 & 0,2487 \\
Residuos & 18 & 28,8267 & 1,60148 & & \\
Total (Corregido) & 26 & 51709,7 & & & \\
\hline
\end{tabular}


colorante rojo Punzó, mientras que para la variación entre $500-1000 \mathrm{mg} / \mathrm{L}$ de rojo punzó no se presenta una variación significativa entre los dos niveles, presentándose una pequeña disminución en el porcentaje de biodegradación del colorante rojo Punzó a medida que se incrementa la concentración del colorante.

\section{Discusión}

Como se evidenció el colorante rojo Punzó es susceptible de ser biodegradado por medio de digestión anaerobia. En el presente trabajo se presentan porcentajes de remoción superiores al $90 \%$ de dicho colorante, por lo tanto, se concluye que los colorantes azoicos como el rojo punzó se pueden degradar por vía anaerobia.

Por otra parte, se observa que la presencia del almidón como cosustrato no potenció ni favoreció la aclimatación y posterior biodegradación anaerobia del colorante rojo punzó mediante la ecología microbiana alcanzada en los reactores y en el proceso de tratamiento del colorante teniendo en cuenta los diferentes niveles y tratamientos experimentales evaluados en este estudio.

Sin embargo, se observó un equilibrio en la ecología microbiana de los reactores, debido a que se presentaron bajas concentraciones de bacterias sulfatoreductoras; teniendo en cuenta que estas compiten con las bacterias metanogénicas por los sustratos comunes, disminuyendo la capacidad de generación de biogás como subproducto de la biodegradación anaerobia de contaminantes.

Es de suma importancia el control de las variables fisicoquímicas y microbiológicas para el adecuado funcionamiento del sistemas de biodegradación anaerobia con el fin de alcanzar mejores porcentajes de degradación y mineralización de los compuestos sometidos a este tipo de tratamiento, debido a que un control inadecuado de estas variables puede afectar negativamente los equilibrios en la ecología microbiana, desfavoreciendo las rutas metabólicas de la degradación anaerobia, presentándose acidificación del medio e inhibición de la producción de biogás.

Se observa como los procesos de digestión anaerobia, son tecnologías apropiadas y ambientalmente sostenibles (22) para lograr la biodegradación de compuestos recalcitrantes y persistentes como es el caso del colorante azoico rojo Punzó, y de esta forma, alcanzar la disminución de los impactos negativos sobre nuestro entorno inmediato, contribuyendo a generar iniciativas de sostenibilidad ambiental para nuestra sociedad.

\section{Referencias}

1. Arroyave R., J. A., Garcés G., L. F., y Arango R. A. Mineralización del colorante Tartrazina mediante un proceso de oxidación avanzada. Revista Lasallista de Investigación. ISSN 1794 - 4449. Vol 6 No 2 (Julio - Diciembre) 2009. pp27 - 34

2. Arroyave R., J. A., Garcés G., L. F. y Mejía T., J. Empleo del reactivo de fenton para la degradación del colorante tartrazina. Revista Lasallista de Investigación. ISSN 1794-4449. Vol 6 No 1 (Enero-Junio) 2009. pp27-34.

3. Arroyave R., J. A., Garcés G., L. F. Arango R. A, Agudelo L., C. M. y Martínez R., C. A. Degradación del colorante tartrazina mediante fotocatálisis heterogénea empleando lámpara de luz ultravioleta. Revista de Producción Más Limpia. ISSN 1909 - 0455. Vol 3 No 2 (Julio Diciembre) 2008. pp21 - 32 .

4. Arroyave R., J. A., Garcés G., L. F. Arango R. A, Agudelo L., C. M. y Martínez R., C. A. Degradación del colorante tartrazina mediante fotocatálisis homogénea empleando lámpara de luz ultravioleta. Revista de Producción Más Limpia. ISSN 1909-0455. Vol 3 No 1 (Enero-Junio) 2008. pp25 - 35.

5. Arroyave R., J.A., Garcés G., L. F. Arango R. Ay Agudelo L., C. M. Photo degradation of the tartrazine dye by means of photofenton, using an ultra violet light lamp. Revista Lasallista de Investigación. ISSN 1794- 4449. Vol 5 No 2 (Julio - Diciembre) 2008. pp6 - 12.

6. Arroyave R., J. A., Garcés G., L. F., Arango R., A. y Agudelo L., C. M. La Tartrazina, Un colorante de la industria agroalimentaria, degradado mediante procesos de oxidación avanzada. Revista Lasallista de Investigación. ISSN 1794 - 4449. Vol 5 No 1 (Enero - Junio) 2008. pp20 - 27.

7. Rajaguru, P., et al. 2002. Genotoxicity evaluation of polluted ground water in human peripheral blood lymphocytes using the comet assay. Mutation Res. 517, p. 29-37.

8. Umbuzeiro, G.A., et al. 2005. The contribution of azo dyes to the mutagenic activity of the Cristais River. Chemosphere 60, pp55-64.

9. Golab, V., Vinder, A., Simonic, M. 2005. Efficiency of the coagulation/ flocculation method for the treatment of dye bath effluent. Dyes and Pigments 67, pp93-97.

10. Lopez-Grimau, V., Gutierrez, M.C. 2005. Decolorization of simulated reactive dyebath effluents by electrochemical oxidation assisted by UV light. Chemosphere 62 (1), pp106-112.

11. Rai, H., et al. 2005. Removal of dyes from the effluent of textile and dyestuff manufacturing industry: a review of emerging techniques with reference to biological treatment. Crit. Rev. Environ. Sci. Tech. 35, pp219-238.

12. Van der Zee, F.P., Villaverde, S. 2005. Combined anaerobic-aerobic treatment of azo dyes - a short review of bioreactor studies. Wat. Res. 39, pp1425-1440.

13. Pandey, A., Singh P., Iyengar L. 2007. Review: Bacterial decolorization and degradation of azo dyes. Internat. Biodeterioration and Biodegradation. pp54, 73-84.

14. Díaz- Baez, M. C. Espitia, S.E., Molina, F. "Digestión Anaerobia una aproximación a la tecnología”. Universidad Nacional de Colombia instituto de Biotecnología. 1 ed. 2002. pp39- 63.

15. Naranjo T., F., González D., M. E., Molina P., F. Evaluación microbiológica de un lodo crudo proveniente de la PTAR del municipio del Retiro y del mismo lodo aclimatado a condiciones anaerobias. Revista Facultad de Ingeniería. ISSN 0120-6230. Vol 22 Junio de 2001. pp22 - 28.

16. Chinwetkitvanich, S., Tuntoolvest, M., Panswad, T., 2000. Anaerobic decolorization of reactive dyebath effluents by a two stage UASB system with Tapioca as co-substrate. Wat. Res. 34, pp2223-2232.

17. Willetts, J.R.M. et al. 2000. The use of thermophilic anaerobic system for pretreatment of textile dye wastewater. Wat. Sci. Tech. 42 (5-6), pp309-316.

18. Talarposhti, A.M., Donnelly, T., Anderson, G.K. 2001. Colour removal from a simulated dye wastewater using a two phase anaerobic packed bed reactor. Wat. Res. 35, pp425-432.

19. Yoo, E.S., Libra, J., Adrian, L., 2001. Mechanism of decolorization of azo dyes in an anaerobic mixed culture. J. Environ. Eng. (ASCE) 127, pp844-849.

20. Standard methods for the examination of water and wastewater. 2005. $21^{\text {th }}$ Washington: Centennial Edition.

21. Cambell. R,. 2001. Ecología Microbiana. México, Limusa. p268.

22. Arroyave Rojas, Joan Amir y Gárces Giraldo, Luís Fernando. Tecnologías Ambientalmente Sostenibles. En: Revista de Producción Más Limpia. Vol. 1, No. 2 (Julio - Diciembre) 2006. pp78-86 